\title{
A comprehensive model of the deformation process in the Nagamachi-Rifu Fault Zone
}

\author{
Yoshihisa Iio ${ }^{1}$, Takeshi Sagiya ${ }^{2}$, Norihito Umino ${ }^{3}$, Takuya Nishimura ${ }^{4}$, Kunihiko Takahashi $^{5}$, and Takahiro Homma ${ }^{5}$ \\ ${ }^{1}$ Research Center for Earthquake Prediction, Disaster Prevention Research Institute, Kyoto University, Gokasho Uji 611-0011, Japan \\ ${ }^{2}$ Research Center for Seismology, Volcanology and Disaster Mitigation, Nagoya University, Chikusa-ku, Nagoya 464-8602, Japan \\ ${ }^{3}$ Research Center for Prediction of Earthquakes and Volcanic Eruptions, Graduate School of Science, \\ Tohoku University, Aoba-ku, Sendai, Miyagi 980-8578, Japan \\ ${ }^{4}$ Geographical Survey Institute, Kitasato-1, Tsukuba, Ibaraki 308-0811, Japan \\ ${ }^{5}$ Fuji Research Institute Corporation, Chiyoda-ku, Tokyo 101-8443, Japan
}

(Received May 29, 2004; Revised August 24, 2004; Accepted September 7, 2004)

\begin{abstract}
A two-dimensional finite element model was constructed along a cross section almost perpendicular to the Nagamachi-Rifu Fault Zone, in order to clarify the stress accumulation process on an intraplate earthquake fault. We explain the surface deformations observed by the dense GPS network and leveling surveys using models with heterogeneities in the crust. These heterogeneities are identified from various geophysical surveys in the region. We found that the observed surface deformations cannot be explained by a model having a weak zone in the upper crust, but can be explained by models having a weak zone in the lower crust. Models having an aseismic fault or fault zone in the lower crust can reproduce the spatial pattern of the observed deformations, but amplitudes predicted by these models are smaller than those observed. The weak zone in the lower crust probably plays an important role in the stress accumulation process on the Nagamachi-Rifu fault zone.
\end{abstract}

Key words: Intraplate earthquake, lower crust, ductile fault zone, stress accumulation, plate boundary.

\section{Introduction}

In order to understand the origin of intraplate earthquakes, various surveys and investigations have been conducted around the Nagamachi-Rifu Fault Zone, which runs through Sendai city, Northern Japan. These have included, crustal movement observations with a dense GPS array (Nishimura et al., 2004), resistivity structure surveys using the magnetoteluric (MT) method (Ogawa et al., 2002, 2003), gravity survey (Komazawa and Mishina, 2002), reflection and refraction seismic surveys (Sato et al., 2002; Umino et al., 2002a; Nakamura et al., 2002; Imanishi et al., 2002), seismic observations (Nakajima et al., 2004), and receiver function analyses (Yoshimoto et al., 2001). Utilizing these observational results, we constructed a first-order approximation model of the stress accumulation process of the Nagamachi-Rifu Fault Zone (NRFZ) with the finite element method.

First we simplify the observational results to model heterogeneities around the NRFZ. Then, we calculate with a 2D finite element model, the deformation in the crust and upper mantle caused by the modeled heterogeneities under the interaction between the subducting oceanic plate and the intraplate lithosphere.

Iio and Kobayashi (2002) examined several previously proposed models for the generation of large intraplate earthquakes, and found the most plausible to be the 'localized

Copy right(c) The Society of Geomagnetism and Earth, Planetary and Space Sciences (SGEPSS); The Seismological Society of Japan; The Volcanological Society of Japan; The Geodetic Society of Japan; The Japanese Society for Planetary Sciences; TERRAPUB shear model'. In this model seismogenic faults have downward extensions in the lower crust and the localized shear deformations in the low viscosity fault zone accumulate stress on the seismogenic faults (e.g., Sibson, 1983).

The 'localized shear model' is a 'low-strength model', in which stress is accumulated above the regions of low viscosity in the lower crust and/or upper mantle. Other models consider that the region of low viscosity is not confined to a localized ductile fault zone, but is widely distributed throughout a volume (e.g., Liu and Zoback, 1997; Kenner and Segall, 2000).

In this study, we will examine the conclusions of Iio and Kobayashi (2002) by modeling an individual intraplate earthquake fault.

\section{Summary of Observational Results}

First, we summarize the observational results about the structure and deformation around the NRFZ.

The three-dimensional seismic velocity structure in the region of the NRFZ was estimated by travel-time tomography (Nakajima et al., 2004). Several anomalies were detected and are schematically illustrated in Fig. 1; a) a low-Vp and low-Vs anomaly close to the surface trace of the fault at depths down to about $6 \mathrm{~km}, \mathrm{~b}$ ) a low-velocity anomaly with moderate $\mathrm{Vp} / \mathrm{Vs}$ at a depth of about $15 \mathrm{~km}$, and a low-Vs and high-Vp/Vs area at depths of 20-30 km beneath the $\mathrm{Ou}$ back-bone range (OUBR). Further, a low velocity anomaly with high- $\mathrm{Vp} / \mathrm{Vs}$ in the uppermost mantle is detected beneath the OUBR.

The low resistivity anomalies are also detected by the MT method for the upper parts of anomalies a) and b) (Ogawa 


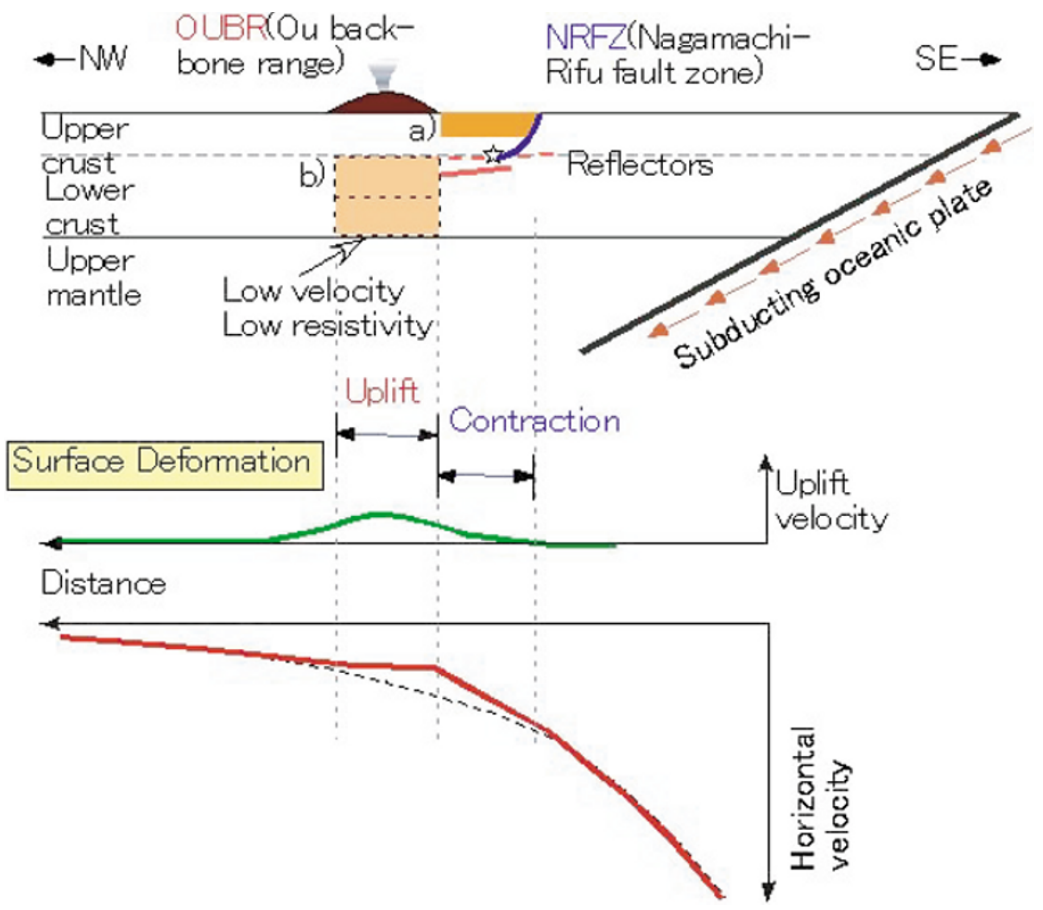

Fig. 1. Summary of the structure and surface deformation around the Nagamachi-Rifu Fault Zone (NRFZ) and Ou back-bone range (OUBR). A two dimensional cross section perpendicular to the NRFZ is schematically shown in the upper panel. a) low velocity and anomaly in the upper crust b): low velocity and low resistivity anomaly. Star: aftershock area of the M MAA 5.2 earthquake (Umino et al., 2002b). The aftershock area is thought to be located on the deepest portion of the seismogenic Nagamachi-Rifu fault zone. Broken line: reflector detected by reflection seismic surveys (Nakamura et al., 2002). The thick line beneath the star indicates S-wave reflectors (Umino et al., 2002a). The crustal deformation around this NKTZ is schematically illustrated in the lower panel.

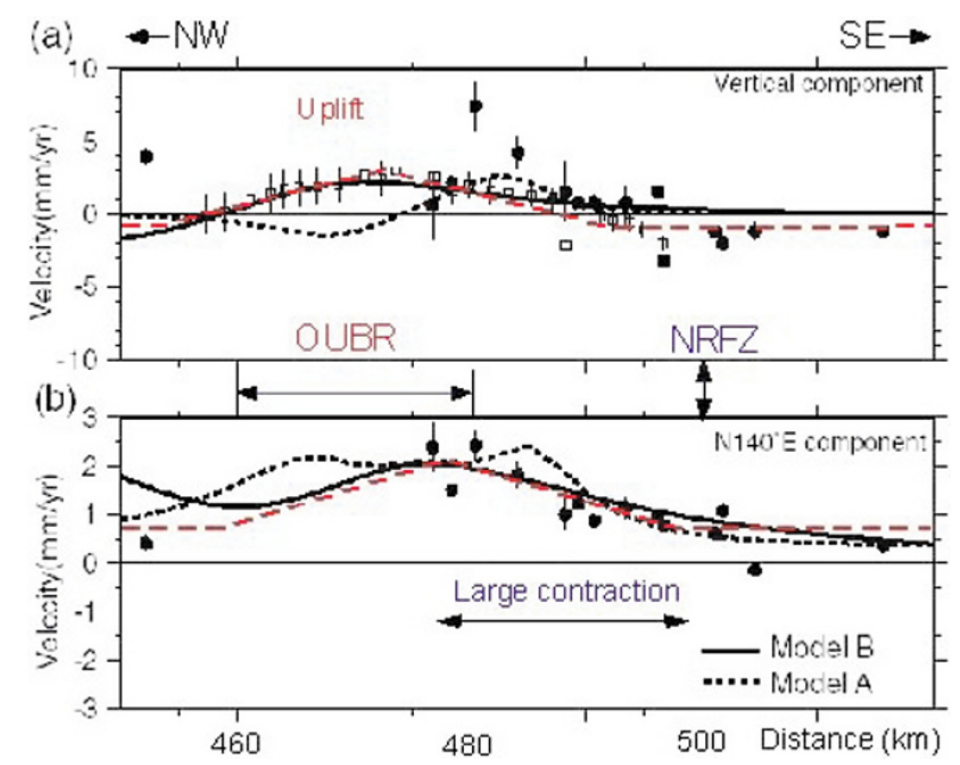

Fig. 2. Residual velocity profiles perpendicular to the NRFZ (modified after Nishimura et al., 2004) (a) Vertical, and (b) N140 ${ }^{\circ}$ e components. Open and closed circles indicate the corrected leveling and GPS velocities, respectively. We simplified these data profiles as shown by the red broken lines that consist of triangles of width $40 \mathrm{~km}$ and heights of $1.5 \mathrm{~mm} / \mathrm{yr}$ and $4 \mathrm{~mm} / \mathrm{yr}$, for horizontal and vertical velocity, respectively. Black dotted and solid curves are velocities calculated for Models A and B, respectively, estimated by kinematic inversion analyses (Nishimura et al., 2004), in which slip velocities of about $1 \mathrm{~cm} / \mathrm{yr}$ on detachment faults are assumed.

et al., 2002, 2003). Regions beneath the low resistivity anomalies also possibly have low resistivities, however, the MT method does not have sufficient resolution beneath the low resistivity layer. These anomalies are thought to be reliable since they were detected by two different kinds of observations.
Reflection and refraction seismic surveys detected reflectors in the downward (westward) extension of the aftershock area of the $\mathrm{M}_{\mathrm{JMA}} 5.2$ earthquake, as schematically illustrated by the broken line in Fig. 1 (Nakamura et al., 2002; Research Group for Deep Structure of NagamachiRifu Fault, 2002). The aftershock area is thought to be lo- 


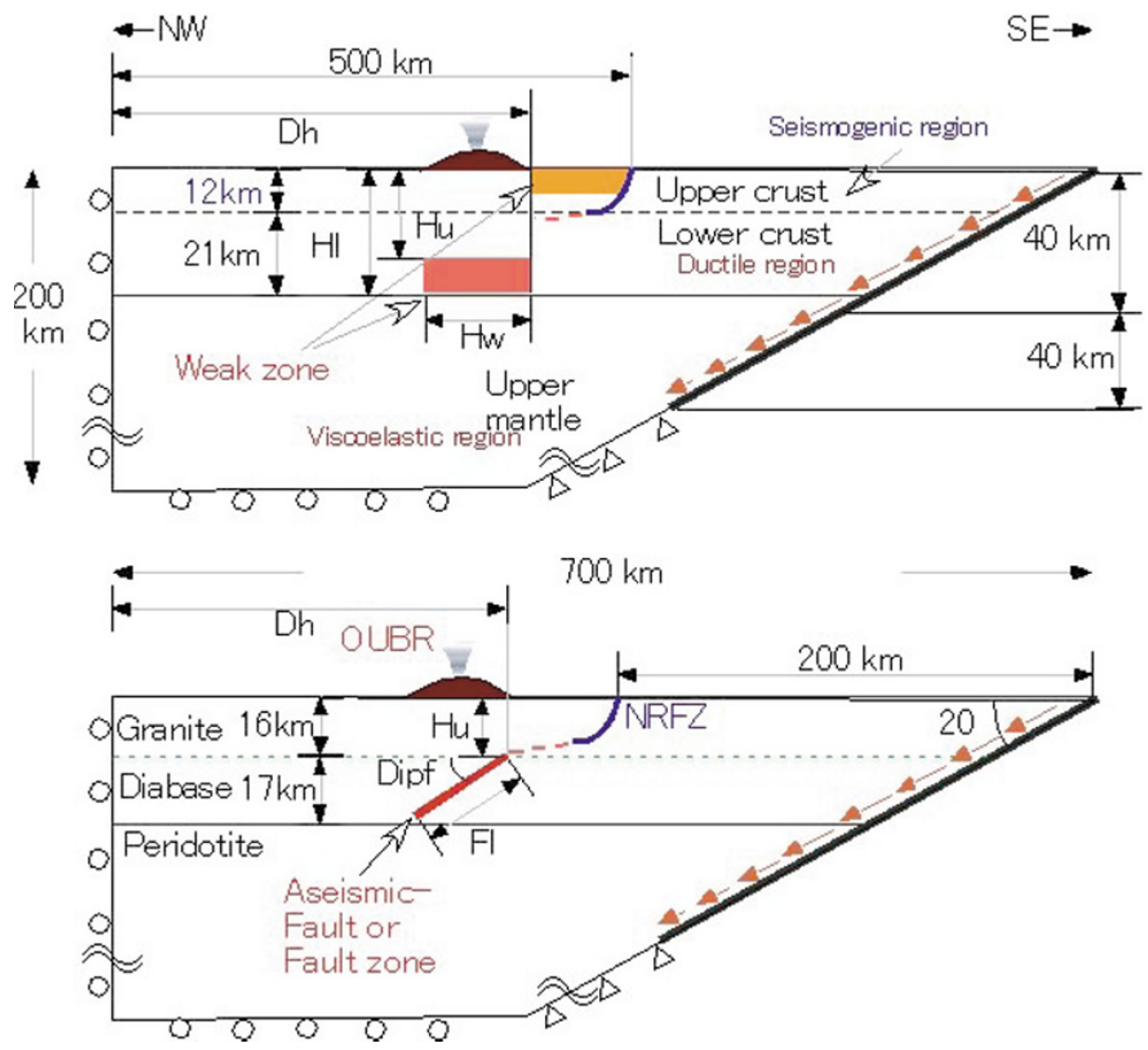

Fig. 3. A two-dimensional finite element model with various heterogeneities. Parameters that characterize the heterogeneities are explained in Table 2. The bottom of the seismogenic region is about $12 \mathrm{~km}$ around this area (Umino et al., 2002b) and faults are thought to deform in a ductile manner below this depth. We assume that the upper and lower parts of the crust consist of granite and diabase, respectively.

Table 1. Elastic moduli and viscosities. The viscosities are computed from the relaxation time of 5 years. The values of viscosities in the parentheses are those of the assumed heterogeneities.

\begin{tabular}{lcccc}
\hline & $\begin{array}{c}\text { Young modulus } \\
(\mathrm{Pa})\end{array}$ & Poisson ratio & $\begin{array}{c}\text { Density } \\
\left(\mathrm{kg} / \mathrm{m}^{3}\right)\end{array}$ & $\begin{array}{c}\text { Viscosity } \\
\left(\mathrm{Pa}^{*} \mathrm{~s}\right)\end{array}$ \\
\hline Upper crust & $9.13 \times 10^{10}$ & 0.24 & 2650 & $\left(5.8 \times 10^{18}\right)$ \\
Lower crust & $1.06 \times 10^{11}$ & 0.28 & 2940 & $\left(6.5 \times 10^{18}\right)$ \\
Mantle & $1.90 \times 10^{11}$ & 0.26 & 3310 & $1.2 \times 10^{19}$ \\
\hline
\end{tabular}

cated in the deepest portion of the seismogenic NagamachiRifu fault zone (Umino et al., 2002b), as shown by a star in Fig. 1. A reflector is also detected on the opposite side (southeast) of the aftershock area. The region in and around this (southeast) reflector is characterized by low resistivities, while the downward (northwestward) extension by high resistivities. S-wave reflectors are also identified below the aftershock area (Umino et al., 2002a).

The GPS array and leveling revealed heterogeneous crustal deformations west of the NRFZ (Nishimura et al., 2004). The residual vertical and horizontal velocity profiles are shown in Fig. 2, which were obtained by subtracting the effect of the relative plate motion from the original data. A decreasing horizontal velocity with distance (southeastward, +) shows a large strain rate, indicating the increasing westward velocity with distance. It is found that uplifts mainly occur in the OUBR while a large strain rate is seen between the NRFZ and OUBR. Thus, the crustal deformation around this area is characterized by a large contraction and small uplift between the NRFZ and the OUBR, and a small contraction and large uplift in the OUBR, as schematically illustrated in Fig. 1.

\section{Model}

A two-dimensional finite element model was constructed along a cross section almost perpendicular to the NRFZ in the NW-SE direction, using the finite-element code, Abaqus (Hibbitt et al., 2001). The framework of the FEM model is shown in Fig. 3. The inland plate is dragged by the subducting oceanic plate at a rate of $10 \mathrm{~cm} / \mathrm{yr}$ to a depth of 40 $\mathrm{km}$ and the rate decreases to zero linearly with depth from 40 to $80 \mathrm{~km}$. Below $80 \mathrm{~km}$, the relative displacement on the plate boundary is zero to be consistent with the assumptions of the 'back slip model'. Displacements at the left and 
Table 2. Parameters of heterogeneities. These parameters are explained in Fig. 3. Dh: distance from the plate boundary to heterogeneities. Hu: depth of the upper limit of the heterogeneities. Hl: depth of the lower limit of the heterogeneities. Dipf: dip angle of faults or a fault zone. Fl: length of the faults or fault zone.

\begin{tabular}{ccccccc}
\hline No. & & $\mathrm{Dh}(\mathrm{km})$ & $\mathrm{Hu}(\mathrm{km})$ & $\mathrm{Hl}(\mathrm{km})$ & Dipf & $\mathrm{Fl}(\mathrm{km})$ \\
\hline 1 & Lower crust & 480 & 12 & 33 & & \\
2 & Lower crust & 480 & 24 & 33 & & \\
3 & Lower crust & 480 & 12 & 24 & & \\
4 & Upper crust & 500 & 0 & 6 & & \\
5 & Fault (short) & 480 & 16 & & 10 & 21 \\
6 & Fault (long) & 480 & 16 & & 10 & 82 \\
7 & Fault zone & 480 & 22 & & 30 & 22 \\
\hline
\end{tabular}
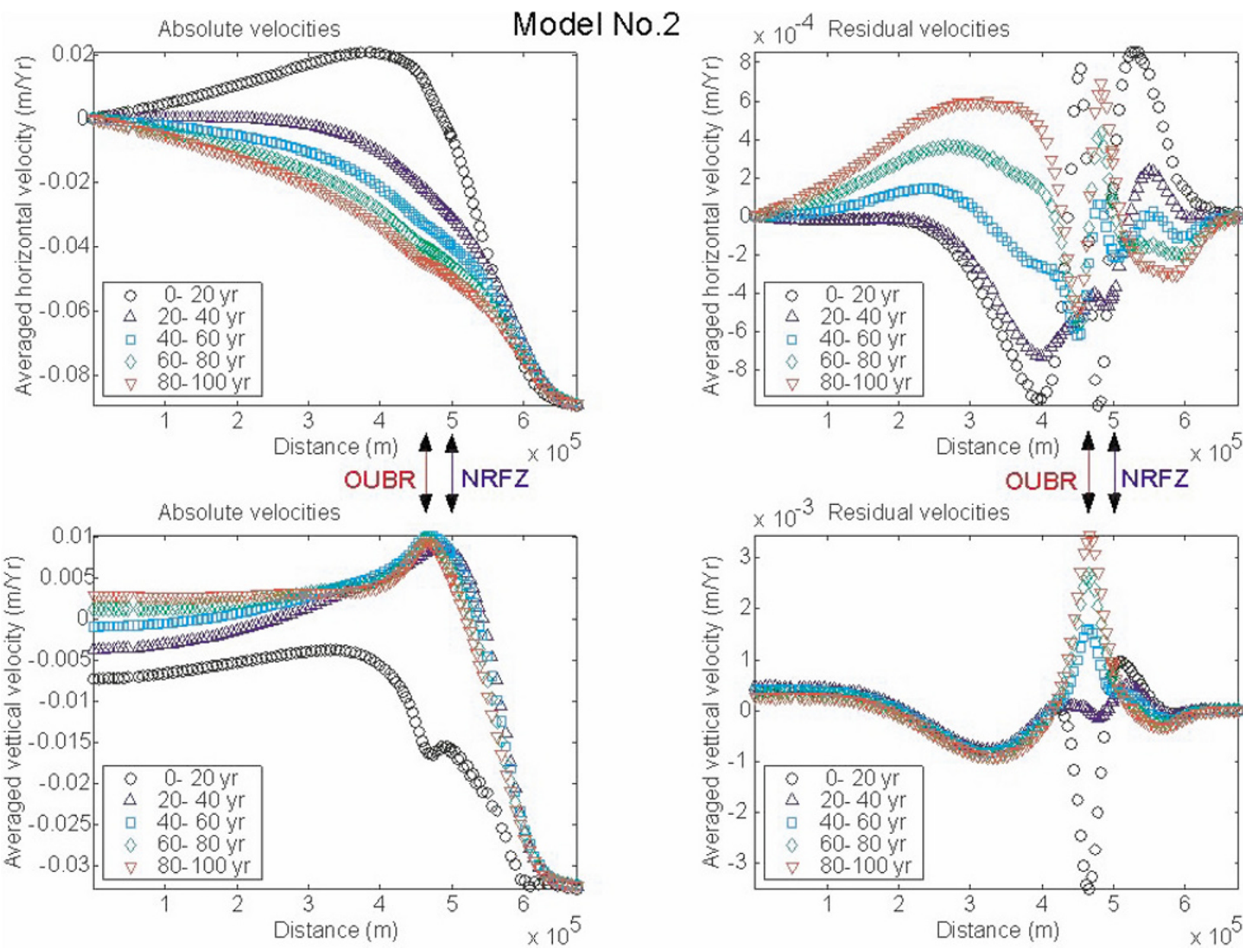

Fig. 4. Horizontal and vertical velocities at 20 year intervals for the heterogeneity of model No. 2. Absolute velocities are shown in the left-hand side panel, while residual velocities relative to those for a model with no heterogeneity, are shown in the right-hand side panel.

lower boundaries are free only in the direction parallel to the boundaries. The crust is assumed to be elastic, since the time scale of this simulation is comparable to or shorter than a recurrence interval of intraplate earthquakes, namely several hundreds years. The upper mantle is assumed to be visco-elastic with a relaxation time of $5 \mathrm{yr}$. In this study, the rheological property of visco-elastic bodies is assumed to be Maxwellian in shear deformation and Hookian in bulk deformation. The values of elastic moduli and viscosities assumed in this study are listed in Table 1.

We assumed several heterogeneities according to the ob- servational results, mainly velocity anomalies, as shown in Table 2 and Figs. 1 and 3. 1) to 4) are weak zones in the upper and lower crust, for simplicity, these heterogeneities are assumed to be visco-elastic bodies with a relaxation time of 5 yr. 5) and 6) are aseismic faults with a small dip angle of 10 degrees. These aseismic faults are represented by a Master and Slave technique (Melosh and Raefsky, 1981) and zero friction is assumed. 7) is a ductile fault zone of width $3 \mathrm{~km}$ and a dip angle of 30 degrees. This fault zone is also assumed to be a visco-elastic body with a relaxation time of $5 \mathrm{yr}$. The aseismic faults are located in the down- 


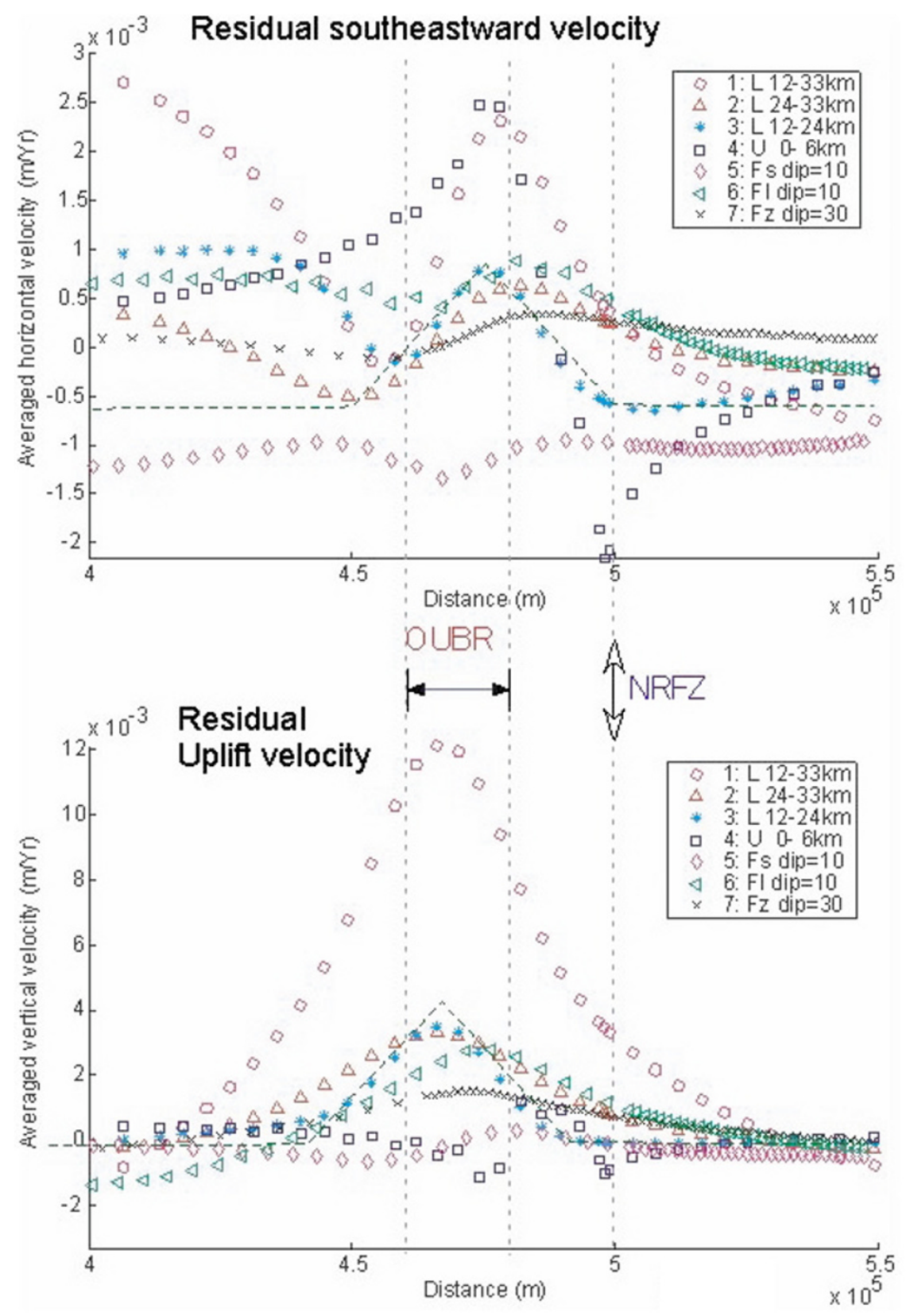

Fig. 5. Residual horizontal (upper panel) and vertical velocities (lower panel) are illustrated for all the heterogeneities for the 20 years before the next interplate earthquake.

ward (westward) extension of the NRFZ, however there is a region between the aseismic faults and the deepest portion of the NRFZ (indicated by a star in Fig. 1). These heterogeneities are also located apart from the deepest portion. This is because the region in the westward extension of the NRFZ is characterized by a high velocity and high resistivity (Nakajima et al., 2004; Ogawa et al., 2002, 2003).

After gravitational compensation settled, the inland plate was submitted to drag from the subducting plate for 1000 yr. Then, interplate earthquakes were generated by forcing displacements in the reverse direction on the plate boundary of the inland plate at every $100 \mathrm{yr}$. The magnitude of the displacement is equivalent to the amount of the back slip for $100 \mathrm{yr}$ with a maximum slip of $10 \mathrm{~m}$. The reason the inland plate was first subjected to drag for $1000 \mathrm{yr}$ is that the absolute shear stress is estimated to be roughly one order of magnitude greater than stress drops of the interplate earthquakes, as observed in the results of stick-slip rock mechanics experiments. After several earthquakes were generated, the system response becomes stable.

Since the purpose of this study is to construct a first-order approximation model of the stress accumulation, we will investigate which aspects of the heterogeneities can explain gross features of the crustal deformation around the NRFZ, as shown in Fig. 2 by the broken lines.

\section{Results}

Figure 4 shows typical examples of the results which were obtained after four interplate earthquakes were generated for heterogeneity No. 2. Absolute horizontal and vertical velocity profiles at the surface for every 20 years are shown on the left-hand side of the Fig. 4, with residual 
horizontal and vertical velocities relative to those for the model with no heterogeneity, shown on the right-hand side. Postseismic deformations dominate for the first 20 years, however, they quickly diminish and the effect of the heterogeneity is dominant for latter periods.

Residual horizontal and vertical velocity profiles are illustrated for all of the heterogeneities for the 20 years before the next interplate earthquake in the upper and lower panels in Fig. 5, respectively. For the horizontal velocities, all traces, except one, show increasing velocities in the OUBR while decreasing velocities between the OUBR and NRFZ. The exception is No. 5, the short aseismic fault with a dip angle of 10 degrees, which shows only a small perturbation resulting from this heterogeneity. For the vertical velocities, uplifts occur in the OUBR for all heterogeneities except for No. 4. The results of No. 4 show uplifts between the OUBR and NRFZ. This is not consistent with the observations.

The results, except for models No. 4 and No. 5, are qualitatively in accordance with the observations shown in Fig. 2. Quantitatively, model No. 3 appears to explain the observations well. The broken lines in Fig. 5 are almost the same as those shown in Fig. 2, slightly shifted to fit the results of model No. 3. It is found that the results of model No. 3 fit the observations well, as represented by broken lines with their amplitudes and widths of the triangular pulses. Furthermore, the difference in the peak location of the pulses between the horizontal and vertical velocity profiles is well reproduced by the model. The other models, except for No. 4 and 5, can also explain the difference. On the other hand, the results of model No. 6 , the asiesmic fault, and model No. 7, the fault zone, do not quantitatively fit the observations. Perturbations resulting from fault motions appear to be small, in particular between the OUBR and NRFZ, in spite of their long fault lengths and zero friction or large dip angle. The perturbations are not greatly different when we assumed much smaller viscosities in the fault zone.

\section{Discussion and Concluding Remarks}

We constructed finite element models for the stress accumulation process around the NRFZ and compared calculated surface deformations with observations. Model No. 4, which assumed a weak zone in the upper crust, predicts that contraction and uplift occur above the heterogeneity, namely between the NRFZ and OUBR, and this result is not consistent with the observations. In models No. 1 to 3 , which assumed a weak zone in the lower crust beneath the OUBR, uplift occurred above the weak zones, while it appears that a contraction is smaller above the weak zones compared to the surrounding area. This is probably because uplift motions cancel horizontal contractions to some extent. These models are in accordance with the observations. Models No. 5 to 7, which assumed an aseismic fault or fault zone in the lower crust, show almost the same results as the models of the heterogeneities in the lower crust, but the amplitudes of the surface deformations are smaller than the observations. In particular model No. 5 with the short aseismic fault cannot explain the observations.

Thus, we conclude that the weak zone in the upper crust does not reproduce the observed crustal deformation pattern around the NRFZ. Further, the short aseismic fault with a small dip angle is also not consistent with the observations, since the total force acting on the fault is not large enough to generate a large slip.

It seems that the model with the weak zone in the upper portion in the lower crust (model No. 3) explains the observations well. Further, this heterogeneity is detected by both the seismic tomography and resistivity measurements. However, the amplitudes of the surface deformations predicted by these models may change with different assumptions of the viscosity in the weak zone, the time after the occurrence of an interplate earthquake, and the magnitude of the drag from the subducting plate. Although we have to justify these assumptions before we choose the best model, the results obtained in this study show an upper limit of deformation velocities, since the viscosity is set to be fairly small, the time after the interplate earthquake is close to $100 \mathrm{yr}$, and the upper part of the seismogenic plate boundary fault is assumed to be completely locked. Therefore, we do not conclude that the model No. 3 is the best model, but suggest that the models having the weak zone in the lower crust are more plausible than those having an aseismic fault or fault zone. In this study we assume models with only one aseismic fault or fault zone, however, the observations may be explained by a weak zone that consists of several fault zones, as introduced by lio et al. (2004).

As shown in Fig. 1, the heterogeneities in the lower crust are separated from the deepest portion of the seismogenic fault. Thus, it is likely there exists a downward extension of the NRFZ in the region between the heterogeneities and the deepest portion of the seismogenic fault, since the region should have been deformed over a longer time scale. Reflection surveys detected reflectors in this area, although the other survey results indicate that the region is now characterized by high velocities and resistivities. Anyway, the results obtained in this study suggest that the heterogeneities in the lower crust play an important role in stress accumulation process on the seismogenic fault and also its downward extension.

Acknowledgments. This study is partly supported by a grant from the Comprehensive Joint Research of the Special Coordination Funds for Promoting Science and Technology, 'the Comprehensive Research on Slip and Flow Processes in and below the Seismogenic Region'. The authors are grateful to Jun'ichi Nakajima and Takeyoshi Yoshida, Tohoku University for valuable discussions. They also thank James Mori Jiro for his critical review. The authors are grateful to Bruce Hobbs and Shui-Beih Yu for their critical reviews and valuable suggestions.

\section{References}

Hibbitt, Karlsson, and Sorensen, Abaqus/Standard User's Manual, vol. 1 and 2, version 6.2, Hibbitt, Karlsson, and Sorensen Inc., Pawtucket, 2001.

Iio, Y. and Y. Kobayashi, A physical understanding of large intraplate earthquakes, Earth Planets Space, 54, 1001-1004, 2002.

Iio, Y. and Y. Kobayashi, Is the plastic flow uniformly distributed below the seismogenic region?, Tectonophysics, 364, 43-53, 2003.

Iio, Y., T. Sagiya, and Y. Kobayashi, What controls the occurrence of shallow intraplate earthquakes?, Earth Planets Space, 56, this issue, 1077-1086, 2004.

Ikawa, T., T. Kawanaka, S. Kawasaki, A. Hasegawa, N. Umino, A. Nakamura, and H. Ito, Seismic reflection survey of the deep structure of Nagamachi-Rifu fault, Northeastern Japan, Proceedings of International 
Symposium on Slip and Flow in and below the Seismogenic Region, in Sendai, Japan, 44, 2001.

Imanishi, K., H. Ito, Y. Kuwahara, Y. Mamada, T. Yokokura, N. Kano, K. Yamaguchi, and A. Tanaka, Deep structure of the Nagamachi-Rifu fault deduced from small aperture seismic array observations, Earth Planets Space, 54, 1033-1038, 2002.

Kenner, S. and P. Segall, A mechanical model for intraplate earthquakes: Application to the New Madrid, Science, 289, 2329-2332, 2000.

Komazawa, M. and M. Mishina, Caldera structure inferred from gravity anomalies west of Nagamachi-Rifu Fault, Northeast Japan, Earth Planets Space, 54, 1049-1053, 2002.

Liu, L. and M. D. Zoback, Lithospheric strength and intraplate seismicity in the New Madrid seismic zone, Tectonics, 16, 585-595, 1997.

Melosh, H. J. and A. Raefsky, A simple and efficient method for introducing faults into finite element computations, Bull. Seism. Soc. Am., 71, 1391-1400, 1981.

Nakajima, J., A. Hasegawa, S. Horiuchi, K. Yoshimoto, T. Yoshida, and N. Umino, Three-dimensional seismic velocity structure around the Nagamachi-Rifu fault, northeastern Japan, Tectonophysics, 2004 (submitted).

Nakamura, A., Y. Asano, and A. Hasegawa, Estimation of deep fault geometry of the Nagamachi-Rifu fault from seismic array observations, Earth Planets Space, 54, 1027-1031, 2002.

Nishimura, T., T. Sagiya, and S. Miura, Crustal deformation around the Nagamachi-Rifu fault zone and its vicinity (central Tohoku), northeastern Japan, observed by a continuous GPS network, Zisin, 56, 497-509, 2004 (in Japanese with English abstract).

Ogawa, Y., S. Takakura, and Y. Honkura, Resistivity structure across Itoigawa-Shizuoka tectonic line and its implications for concentrated deformation, Earth Planets Space, 54, 1115-1120, 2002.

Ogawa, Y., M. Mishina, Y. Honkura, K. Takahashi, and S. B. Tank, Resistivity imaging of deep extension of Nagamachi-Rifu Fault, Program and abstracts of the 2004 Joint meeting of earth and planetary sciences, S075-014, 2003.

Research Group for Deep Structure of Nagamachi-Rifu Fault (Umino, N. and A. Hasegawa), Seismic reflection survey in Nagamachi-Rifu fault, Sendai, northeastern Japan, Tohoku Geophys. Journ., 36, 311-356, 2002.

Sato, H., T. Imaizumi, T. Yoshida, H. Ito, and A. Hasegawa, Tectonic evolution and deep to shallow geometry of Nagamachi-Rifu Active Fault System, NE Japan, Earth Planets Space, 54, 1039-1043, 2002.

Sibson, R., Continental fault structure and the shallow earthquake source, J. Geol. Soc. London, 140, 741-767, 1983.

Umino, N., H. Ujikawa, S. Hori, and A. Hasegawa, Distinct S-wave reflectors (bright spots) detected beneath the Nagamachi-Rifu fault, NE Japan, Earth Planets Space, 54, 1021-1026, 2002 a.

Umino, N., T. Okada, and A. Hasegawa, Foreshock and aftershock sequence of the 1998 M5.0 Sendai, Northern Japan, earthquake and its implications for earthquake nucleation, Bull. Seismol. Soc. Am., 92, 24652477, 2002b.

Yoshimoto, K., T. Okada, and A. Hasegawa, Seismic observation around the Nagamachi-Rifu fault by using semi-broad-band seismometers, Program and abstracts of the 2001 Joint meeting of earth and planetary sciences, Sz-009, 2001.

Y. Iio (e-mail: iio@rcep.dpri.kyoto-u.ac.jp), T. Sagiya, N. Umino, T. Nishimura, K. Takahashi, and T. Homma 